\title{
Supporting Crossover Students in an Urban School District: A Participatory Project
}

\author{
Robert R. Martinez \\ UNC-Chapel Hill \\ Mark Scholl \\ Wake Forest University \\ Erika Torres \\ Los Angeles County Office of Education \\ Jesus Corral \\ Los Angeles Department of Probation \\ Sandra Naranjo \\ Los Angeles Unified School District \\ Denise Miranda \\ Los Angeles Unified School District \\ Mary Dooley \\ UNC-Chapel Hill
}

\begin{abstract}
This participatory action research (PAR) project describes crossover students' college and career readiness needs in a major west coast urban school district. The paper provided insights from administrator researchers, participants, facilitator, and recommendations for school counselors, educators, and organizations who are thinking of creating more counseling support and educational opportunities for crossover students. The results include the reflections and recommendations of crossover youths (e.g., encourage us, we are worth the rigor). The discussion includes strategies for supporting the academic, career, emotional, and social needs of crossover students.
\end{abstract}

Keywords: Crossover students; school-community partnership; urban schools; college and career readiness.

(C) 2021 Martinez, Scholl, Torres, Corral, Naranjo, Miranda, \& Dooley. Free to copy and share for education and scholarship under a Creative Commons Attribution NonCommercial-NoDerivatives 4.0 License. 


\section{Supporting Crossover Students in an Urban School District: A Participatory Project}

Nationally, the interest in and concern about opportunity gaps of crossover students has inspired a range of mental health and educational supports (Wells et al., 2015). Crossover youth is a parasol term used to describe youth who are involved with both the child welfare and juvenile justice systems either parallel or non-parallel. Understanding crossover youth and their movement or pathways between systems is important for educators, policymakers, and mental health practitioners. By recognizing trends among this population, it is possible to better serve crossover youth and work to prevent situations in which youth are chronically involved in multiple systems and, as a result, exhibit negative life effects (New York City Office of the Mayor, 2015). The majority of work on crossover youth has been done, more specifically, with youth who are simultaneously involved in both the child welfare and juvenile justice systems. These "dually involved" or "crossover" youths are at higher risk for exposure to violence and/or abuse, familial dysfunction, substance use, congregate or group home placement, school dropout, poor grades, truancy, mental health and/or substance use problems, and adult criminality (Ryan et al., 2013). They are also at risk to incur more juvenile, adult, and violent arrests and to be perceived as high risk by system personnel. It is not surprising, therefore, that they are highly represented at deep levels of the juvenile justice system (e.g., comprising out-of-home placement cases), and they tend to receive harsher sanctions or congregate care placement more often than non-dually involved youth (Young et al., 2015). Though they are not a cultural group, they are a subgroup that is maligned, stigmatized and subjected to unfair treatment by education and juvenile justice systems.

Responding to crossover youths' juvenile justice, child welfare, educational, and counseling needs, while balancing accountability and risk reduction, can present a host of problems for those who serve them. Yet, learning how to advocate, collaborate, and share important information between the systems in order to better respond to crossover youth is rarely emphasized, largely because there are few policies and lack of programming in place that require systems to work together (Herz et al., 2012; Wylie, 2014). Advocacy involves educators and counselors challenging or removing systematic barriers that obstruct students' personal, social, academic, and career aspirations (Lee, 1998, 2007). This is complicated by the fact that many actors in these agencies hold different perspectives of youths' needs, with those in the juvenile justice system (JJS) often seeing the youth as a perpetrator in need of rehabilitative services, while child welfare actors (CWA) may view the youth as a victim in need of care and protection and educators seeing the importance of academics as a way to more opportunities (Lutz et al., 2010).

Ultimately, the lack of coordination, communication, and information sharing between the JJS, CWA, and educators has implications not only for these systems, but also for the staff and the crossover youth (and their families) as well. From a systems perspective, three distinct systems responding to a crossover youth with the same or similar services duplicates efforts, which increases costs and distrust among those receiving services and support (Ryan et al., 2013). The duplication of services also means that system personnel are used inefficiently (i.e., their services are duplicated as well), wasting scant resources and increasing costs. Given the different perspectives each system brings to crossover youth (rehabilitation vs. protection vs. education), they might provide different treatments to the youth and family, causing confusion and frustration for the youth and family, as well as expending additional resources. Crossover youth are not necessarily at higher risk for misbehavior, but have more unmet "needs" (perhaps stemming from significant environmental issues), which makes them vulnerable to criminogenic outcomes (Ryan et al., 2013); in these cases, diversion or increased advocacy services-but not punishment-is needed, and doing otherwise may again waste scant system resources. Moreover, responding to a youth who has a multitude of unique needs that have resulted in both child welfare and juvenile justice involvement with a single-systems approach is limited in scope and likely fails to address the core problems that resulted in dual involvement in the first place. Relative to youth who are 
not involved with both the child welfare and juvenile justice systems, crossover youth receive less in the way of programmatic support and resources.

As a way to reduce the disparities and inequalities for crossover youth (e.g., harsher sanctions from the justice system, greater likelihood of referrals to residential treatment centers), a unique partnership and program was created to address these issues and enhance service delivery and/or diversion for these youth. Through development of a crossover youth advocacy model (CYAM), we identified the goals of the program including identifying these crossover youth, coordinating, and informing decisions made by CWA, juvenile justice administrators (JJA) and unified school district (USD) regarding the youth and delivering enhanced, evidenced-based services to them in order to meet their unique educational and counseling needs. To achieve these goals, we adopted elements of the American Counseling Association's Advocacy Competencies Model (ACA-ACM) which has two dimensions: (1) the advocacy domain consisting of three levels (i.e., individual, client or student; school, community or organization; public arena) and (2) the "extent of client involvement" consisting of two levels (i.e., advocacy performed for recipient(s) within a domain, and advocacy performed in collaboration with recipient(s) (Lewis et al., 2003). In implementing the current CYAM we provided both forms of involvement and used advocacy interventions within all three domains. Further, the CYAM addresses systemic barriers and issues facing students by student and agency involvement and level of advocacy intervention between all three agencies which provides techniques to inform decision-making across agencies in order to better serve crossover youth (Lewis et al., 2003). As a "practice model", it provides a conceptual map and organizational ideology regarding how staff can collaborate and advocate on behalf of crossover youth while providing effective services to these youth, while tailoring educational and counseling services to help reduce recidivism through a specialized program.

In this participatory action research (PAR) project, we equally partnered with four administrators across the USD, CWA, and JJS that developed a project to respond to the academic, career, and social/emotional disparities that crossover students encounter. In this project, administrators belonging to a major USD on the west coast, CWA, and JJA developed a Camps-to-College Program (CCP) to enhance the postsecondary opportunities of crossover high school students. The researchers chose PAR because this research approach increases the number of perspectives included in the program deExtravelopment process (Fishman, 2014). By including the perspectives of multiple participants (e.g., crossover youth, school leaders, counselors), we increased the likelihood that the program will be useful in the actual setting (Fishman, 2014). Further, PAR is particularly compatible with the ACA-ACM (Lewis et al., 2003) and with the development of "pragmatic strategies of action and social justice" (Balkin \& Kleist, 2017, p. 235) that will be implemented in the participants' communities that in turn can lead to collective action among community members.

The combination of PAR with the ACA-ACM model is representative of community-based studies that seek to break down barriers and build strong connections. Historically, many communities of color felt exploited by action research studies. This was due, in part, to the lack of a "partnership in participation" approach to the work. Community members felt dismissed and were not taken into consideration in terms of their potential contributions to the research process (Hacker, 2013). Today, community-based PAR involves viewing community members as partners to achieve community benefits for all. Hacker (2013) explains that PAR is most beneficial "when the research was conducted with them not at them." Community members have to be engaged in a collaborative process to uncover, understand, and resolve the issues that harm their communities (McIntyre, 2008). The participants are the main characters in the research. By using collaborative and selfreflective research processes, they take action in improving their condition (McIntyre, 2008). Traditional methods of research are not feasible for this specific type of study due to the necessity of forming a relationship between the researcher and the participants (McIntyre, 2008). 
Like PAR, ACA-ACM is a framework based on the principle that "people who face those problems every day are the ones who hold the key to advocate and come up with creative ways to identify and answer those problems" (McIntyre, 2007, p. 15). Using ACA-ACM approaches can include many overlapping methods that align with PAR, including interviews with community members and emphasizing their importance in building empathy for the target population (i.e., crossover youth and administrators of color). Ethnic minority administrators and marginalized communities (i.e., crossover youth) are rarely included at the research table when evaluating educational, social/emotional, career needs, designing prevention and intervention programs, and assessing barriers and facilitators of care. One reason may be that traditional research approaches can unintentionally silence, rather than foster, individual participants' voices. Consequently, researchers lose the opportunity to capitalize on the unique contributions, experiences, perspectives, and knowledge that community members can provide, informing the development of culturally competent, effective community intervention and prevention efforts. Numerous subgroups of crossover youths exist, pointing to the importance of including all voices at the table to incorporate within-group diversity and advocacy.

\section{The Current Study}

\section{Background: Camps-to-College Program}

In this large urban school district, over 15,000 students come in contact with the county's juvenile justice system. These students are disproportionately Black and Latinx, with 69\% identifying as Latinx, 28\% as Black/ African American, and 3\% as Other. There are 1,508 students between 12 and 20+ years old within the program, with 42\% re-enrolling in Senior High School, 34\% in Continuation High School, 20\% in Community Day School, and $6.1 \%$ in Other. The vast majority of these students have experienced school and home instability, poor school attendance, and academic deficits that result in credit deficiency, putting them at high risk for school failure, pushout, and dropout. Every year, thousands of these students are detained in one of three juvenile halls and approximately 1,400 are currently detained in juvenile camps. Upon release, these students face additional challenges with acceptance and reintegration into their home school.

For the 2016/2017 academic school year, USD, CWA, and JJA created an innovative pilot program named Camp to College High School Program (CCP) to impact the lives of crossover students returning to high school after juvenile detention. The CCP was created to support and enhance student success (i.e., attendance and academic achievement, credit accrual toward a high school diploma or equivalent, high school completion, and college and/or career readiness). The program provided several services including: multi-disciplinary team meetings; school enrollment and assessments; conducting educational assessment and transition plans; attendance/records review; communicating with parents, school, or community staff; coordinating resources and referrals; vocational or college activity; tutoring referral. An evaluation study found that as a result of their sustained programming, participants of CCP had improved attendance, graduation rates, participation in postsecondary education pathways, sense of belonging, and connection to their counselor than those who did not participate. The evaluation also found that because of CCPs sustained programming support to students, community and organization partnerships between USD, CWAs, and JJAs had substantially strengthened the mechanisms for system level advocacy (Toporek \& Daniels, 2018).

\section{Purpose and Research Questions}

Through PAR, this study aims to attend to the voices of crossover students considering that these students' perceptions of college and career (CC) needs have been given limited attention (Nurse, 2013; Osborn \& Belle, 2018) - and to empower students, administrators, and counselors to address the CC needs of participants of the CCP through PAR. This method involves a participative and democratic process among the research participants, administrator researchers, and facilitator researcher that leads to practical outcomes through 
acting towards social change (Balkin \& Kleist, 2017; Reason \& Bradbury, 2012). Through the lens of the ACAACM (Lewis et al., 2003), PAR can address the "power inequities in society" by empowering and giving a voice to crossover students and for those that serve their educational and counseling needs (Reason \& Bradbury, 2012; Toporek \& Daniels, 2018). In this study, we present the experiences of a group of crossover students and administrators who either developed or experienced being in the CCP in hopes that educators and counselors will pause, listen, and be open to new ways of providing opportunities to crossover students as well as thought leaders who had the courage to find a way of supporting these unique students in a major urban school district on the west coast.

Primarily, our study describes opportunity gaps related to educational support systems (i.e., community/ school/organization) and how these educational support systems (i.e., USD, CWA, and JJA) partnered to develop a Camps-to-College program for crossover high school students (i.e., individual/student/client domain). We also describe these efforts (i.e., collective actions at the community/school/organization domain), provide insights from the participants and administrators, as well as provide recommendations for other providers (i.e., public arena domain) looking to support crossover high school students utilizing the Camps-to-College Program.

The administrator research team generated its own World Café style questions, but the research questions listed here are designed to evaluate the overall procedure. The research questions are as follows:

1. How can PAR be used to improve the Camps-to-College Program?

2. How does the inclusion of administrators influence the research process?

3. How does the research process influence crossover youth?

4. How does the inclusion of crossover youth change or improve administrator's responsiveness in enhancing the Camps-to-College Program?

\section{Methods}

A hermeneutic phenomenological paradigm guided the research method. Hermeneutic phenomenology attempts to find, describe, and understand the individual's subjective experience by methodically determining the common and unchanging components, or 'essences' of a particular phenomenon, [e.g., being a crossover youth navigating a CCP or being an administrator responsible for the program] (Balkin \& Kleist, 2017; Van Manen, 1990). Essence stands for those characteristics without which an object would not be what it is. To determine the essence of the phenomenon (or object), the researcher employs the process of free imaginative variation. This process entails the varying of examples and elimination of those elements that are not considered essential to the existence of a particular phenomenon. Although hermeneutic phenomenological research seeks the essence of the experience, there is the realization that the interpretation of that experience is socially constructed by the participants themselves and also co-constructed with the researcher(s). 'Truth' therefore is always inherently tentative and relative to the context of the research. Hence, qualitative methods are well suited for investigating concepts such as views and motivations within the education and counseling community to help explain the processes at work in the uptake of new programming and decision making around crossover youth. The researchers adopted a naturalistic design to explore complexity in this field, adapting from a participatory action-research approach comprising a specialized World (Conversation) Café form of focus group (Alfred, 2011; Guba \& Lincoln, 2004). The Café approach creates a relaxed, informal and imaginative conversational environment, facilitating constructive engagement around complex issues and critical questions.

\section{Participants}

A total of five adults (administrator researchers and facilitator; females, $\mathrm{N}=3$; male, $\mathrm{N}=2$ ) and sixteen crossover youths (female, $\mathrm{N}=9$; male, $\mathrm{N}=7$; younger than 18 years) participated in four small group rounds through World Café format. The World Café approach (Brown et al., 2008) is inspired by the principles of 
participatory research and designed to promote informal/imaginative discussion. It is based on seven key principles: setting a suitable context, creating hospitable space, exploring important questions, encouraging contributions from all, cross-pollinating and connecting diverse perspectives, listening together for insights, and harvesting and sharing discoveries (Brown et al., 2008). The administrator researchers' group was made of four Chicanx/Latinx adults that developed the CCP. All administrator researchers were first generation daughters and sons of immigrant parents and all were bilingual. The administrator researchers were recruited because they had experience in education, child welfare agencies, and the Juvenile Justice System and were interested in learning more about their CCP project and participants to better serve crossover youth. All administrators lived in or went to work in this major urban metropolis, one of the most diverse states in the country. The administrator facilitator (the first author) who has many years of working in the local community was able to recruit from the CCP in the district in partnership with the leadership team, who allowed recruitment. The principal also allowed the administrator research group to use office space in buildings to conduct the research and supported the group in obtaining informed consent and assent from the students and parents. Research participants were all crossovers and ranged in age from 15 to $17(M=16.2, S D=.79)$. The specific heritage of the participants varied as follows: Latinx (9), Black (5), Asian (1), and White (1). The sample was representative of the crossover population throughout the district. Pseudonyms were assigned to each participant team for data reporting in the present study.

\section{Procedure}

\section{Data Collection}

After approval from the primary researcher's institutional review board and from the school district was acquired, local school personnel helped locate students for participation in the present study based on their participation in the CCP. The prospective participants' parents/guardians and students were then contacted and provided with informed consent information. When parents approved, their students were provided with assent requests which they signed to confirm their willingness to participate in the present study. The participants who assented and their parents then received copies of the interview questions approximately one week in advance of the semi-structured interviews with the administrator researchers to allow them time to recollect their experiences and reflect on the content of the interview questions related to the CCP. The questions were written in both English and Spanish.

The PAR team (administrators and facilitator) met on a weekly basis for planning and consultation purposes both before and after World Café style interviews. During the initial meeting, I provided a brief presentation on the literature relating to Spanish-speaking family involvement and the purpose of the study. A nonhierarchical, public sphere was created (Kemmis, McTaggart, \& Nixon, 2013) with the purpose of allowing all members to share responsibility for proposing ideas, collecting data, and interpreting results.

In partnership with the first author (facilitator researcher), the CCP administrator researchers developed a research project on supporting crossover students through the CCP. They were involved in choosing the methodology (World Café style interviews), developing the questions, facilitating the interview questions and providing reflections on solutions for crossover students who enter their CCP. The team met weekly for 1-2 hours on Fridays for approximately 14 weeks via video conference calls and a week-long meeting at one of the camps. Attendance was consistent throughout the entire 14 weeks. For the first few weeks of the project, the administrator researchers learned about educational outcomes in the juvenile justice system through reading academic journals, researching the Office of Juvenile Justice and Delinquency Prevention (OJJDP) website (2016), learning relevant terminology (e.g., crossover youth and school to prison pipeline) and listening to presentations from experts in the field on topics, such as the rates of minorities in juvenile justice, risk factors for juvenile justice involvement, and the impact on mental health for youth involved in juvenile justice. 
Subsequent weeks included reviewing research related topics, such as introducing various methods through experiential activities, consent procedures, protection of human subjects, and so forth. The final few weeks included choosing their methodology, developing questions and focus group guides, and practicing conducting focus groups through World Cafe format (i.e., the group of participants are split up into small groups and do small group rounds of 20- 30 minutes each rotating through several tables and answering a different set of questions at each round). After the project was implemented, the administrator researchers met to debrief about the findings and develop recommendations for policy and program changes regarding crossover students at the CCP.

The day of the research session, the administrator researchers and facilitator researcher arrived early, to set up and practice for the research project. As the event started the administrator researchers led the event and began the process with obtaining informed assent from each participant. They decided to open the event like they had experienced for themselves every week in their own research group. They began the event by asking everyone to introduce themselves and briefly check-in on how they were feeling in the moment and if the group could do anything to support them. Then research participants were divided into four groups, each of which rotated around four stations. Each station in the rotation focused on a specific subtopic on crossover experiences in the educational and juvenile justice system to guide the research participants in discussion. Each topic was selected so that students could directly address barriers, inequities and other problems at the organization or systems level (Lewis et al., 2003; Toporek \& Daniels, 2018). The first topic of discussion at station one was on the perceived impact of race and gender on treatment within education, CWA, and JJA. Research participants at this station were asked to reflect on how gender, stereotype, and culture may influence treatment within all three systems (i.e., Do you feel that because you are a crossover student you are treated different?; Do you feel like crossover students are treated different in school, CWA, and JJA in comparison to someone of a different culture?; Do you feel that crossover students are getting the postsecondary support they need to be successful and what would you suggest?). The second topic, at station two, was about youths' personal experiences with teachers, counselors, probation officers, detention or other aspects of the system. The third station topic included information on academic support and the role of counselors helping them prepare for life during and after high school. At the fourth station, students made recommendations for how the educational, CWA, and JJA could be more helpful in preparing crossover students to access, afford, and transition into postsecondary pathways.

\section{Analysis}

In the data analysis, codes were first assigned and then clustered based on a holistic and line-by-line reading of all transcripts as well as across-case comparisons. Codes were grouped to develop second order constructs that were then organized into clusters, which were given names as provisional themes. Essential themes were determined using the process of imaginative variation (Giorgi, 1997). Imaginative variation is a process whereby the researcher takes concrete examples of a thing or phenomenon, and imaginatively subtracts one feature, then another, from the examples to determine the core or essence of the phenomenon across cases, discovering in the process which features are essential and which are not. In the data, for example, a provisional theme labeled 'flexibility' was considered as a possible essence of subjects' experience. When this theme was checked against the data in the transcripts for validation, 'flexibility' was not uniformly present in all subjects' lived experience. Consequently, it did not meet the criteria for consideration as an invariant component of what it is like to be a crossover youth navigating the CCP. Subtracting this provisional theme, however, illuminated a variant that was essential to the phenomenon that was labeled 'encourage us' and referred to the quality of counseling crossover youth deemed essential. Not only was this essential theme found in the crossover youth experience for all subjects, it embodied the sense of belief and accompaniment that had been ascertained when the provisional theme labeled 'flexibility' was under consideration. Once the essential themes were determined, 
each transcript was recoded using the computer software MaxQDA 12. The researchers used this procedure in order to go through the transcripts again and pull out the relevant quotes to support each theme.

Because qualitative research uses the researcher as the instrument of data collection and the center of the analytic process (Balkin \& Kleist, 2017), it is necessary to establish mechanisms that hold the researcher accountable for the disciplined use of her/his subjectivity. Armour (2002) recommended that the researcher should be internally reflexive and forthcoming about their process. Accordingly, the researchers kept an audit trail of raw data as well as a log of experiences, emotions, insights, and questions by the interviewers. In addition, Ph.D. students and district representatives and an expert in hermeneutics monitored the influence of subjectivity on the data. The Ph.D. students and district representatives 'shadowed' and challenged the research process by independently listening to the audio taped interviews, writing reflections on the interviews, substantiating the determination of the essential themes, and reviewing the findings against the associated quotes from the transcripts. The expert in hermeneutic phenomenological research reviewed methodological procedures, the essential themes, and descriptions of the themes.

\section{Results}

\section{Crossover Youth Reflections}

\section{Building Relationships on Radical Authentic Caring}

If high schools and specialized programs such as the CCP are truly invested in ensuring that these students graduate high school, and are college and career ready, then counselors need not only focus on academic rigor and college resources, but also on taking the time to develop radical authentic relationships with crossover youth. Radical authentic relationships require the ability to be truthful and honest with as well as accepting of all crossover students' unique academic, social and emotional, and career and college needs. Several crossover youths shared similar suggestions on how counselors could particularly improve their efforts in working with them and other students like them. For instance, a common theme of students at station one indicated:

They think it would be better if counselors would actually sit and talk to them and to help them create a plan for jobs, college, and military because a lot of us don't know...even though we are different we still believe - but let's be honest with each other. We all know we are difficult but be honest and let's plan regardless of what's going down in our lives. Counselors and teachers need to work together and figure out how to get us ready for that next level [i.e., college, military, career, parent]. This program we are in gives us that extra stuff and the counselors...principal are really cool and upfront with us and our parents - but in a caring way. They make us feel like we belong even with our baggage.

Station two participants highlighted conversations with school counselors and/or teachers. Sometimes the conversations were more direct, technical, and task oriented and at other times they leaned more towards personal advice. For instance, station two participants noticed:

Teachers are a big part of their success and support system. They don't play around and are upfront with you... if we had a 'serio (serious) question, they don't sugar it up. They tell it like it is. On the other hand, counselors give more technical conversations, but are honest too. They are like, 'do this and this will happen' - no fooling around...straight talk about life and life after high school. It makes us feel listened to and that we all belong. If we had questions or situations; we would ask if you were in my situation what you would do and the teachers were straightforward while counselors were more strategic and cautious...good balance between them - we appreciate it. 
Station three participants also highlighted conversations with counselors: "Like choosing a school and getting the information part, that was important for a career and taking those extra courses at the community college." Station three participants also noted that counselors provided one-on-one points of contact and pamphlets about college and military applications - but also talked about truths and brought real military people in to talk about the military tests (ASVAB) and what your score means and the jobs you can get...but also the things recruiters do to convince you to join...we all liked that."

Station four participants shared examples of memorable conversations that they had with counselors and teachers over the course of the CCP:

Our teachers. They were the ones convincing us, like, go (to college); It's the way to go. Like higher education. Our counselors, everybody was like, you need to go to college. And then we also thought back to our younger grades (i.e., middle school)...they always told us to stay in school because it's always good for us. So just kind of like remembering our past and those that we thought were real, telling us to go stay in school. That was like the big thing that we all remember.

Radical authentic healing through one's culture was a consensus theme across all four stations. This theme entailed the belief that crossover youth are stronger if they are secure within their identity and culture. A station one participant stated, "knowing your culture is powerful, it helps you know your strengths... when counselors and teachers know your culture...we know you care." A Station three youth recognized they (crossover youth) are "healing and learning together in the CCP." A station two youth stated, "our mob (group) is telling their story to counselors and teachers and it makes us feel good and cared for... we are all survivors of the system and our community, sharing our love for food, music, and struggles...learning from others is important and having those counselors and teachers who really care make a difference." A station four youth indicated connecting with community and with family and the importance of intergenerational passing down of "stories, struggles, and cultural knowledge" and having the "power to pass on our stories to others in the CCP":

We all think it is important we tell our stories to future kids like us...look we have parents that are struggling, dead, or in jail...we don't have to keep it a secret with our counselor and teachers, they are down with listening...they (counselors) give us the skills to radically accept our struggle and acknowledge the strengths of them - we learn how to regulate when we are dysregulated...shit, we learned some good stuff here...we noticed our PO (probation officer) asking us how to do some of those skills our counselors are teaching us.

\section{We Are Worth The Rigor}

"We are worth the rigor" emerged as a theme related to crossover youths' perceived belonging within the CCP and future postsecondary pathways. Because all school personnel are often overwhelmed by their individual duties as counselors, ensuring that more crossover youth are career and college ready will require a collaborative effort that could be realized through the integration of college level coursework and college resources in all classrooms, not just advanced placement (AP) or dual enrollment courses. Students were particularly aware of this lack of integration, despite counselors' being generally supportive of students' college aspirations. As one station three participant stated, "I felt it should be the responsibility of counselors to, definitely talk to us more about college and career help. Because, like we said before, you have to go search it. They [teachers] just don't come to you. You have to go find them. We realized that in this program they all come to you." A station two participant also mentioned how "counselors should be a little bit more informative and telling their students how, how this [applying to jobs and college] is done. All of us are very confused on how I should apply. We are lucky we get this extra help." 
All stations' participants indicated, "that if school counselors and teachers keep pushing learning and those hard courses - they would feel like they are worth it." A station one youth indicated, they all like to learn the 'good stuff...real life stuff' - connect it to our life no matter how hard the class is." A station three youth indicated, "school counselors need to make sure they know how students learn and their aspirations to help with their individual learning plans." Transformation of all participants stemmed from counselors and teachers strategically celebrating and encouraging each student to do their best in the program. A station four youth recognized this from counselors through "conversations about courses, adapting and surviving in the community, and breaking through the educational barriers and challenges." A station two youth indicated:

Peoples doubt about us keep us going. The fact that we are doubted, that kind of motivates us to take more harder courses; that lights a fire under us. We are usually forgotten about...this is our way of saying we are worth it and we are going to prove it. We are all going to that next level (i.e., college); we are going to college no matter who supports us or not... we want to be the first.

A station four youth also stated, "they think it kind of goes back to resiliency; just being resilient through everything that's happened. That's pretty much what will get us to college ... being resilient, persevering through everything and knowing what's happening right now is not going to be forever." A station three youth also indicated the importance of pushing through:

The hardest thing for us was knowing our experiences [were] not who we are, like that doesn't define who we are, so just trying to really take that and move forward with that and know that even though we went through all of this, we can still do it. We all struggled with knowing that okay even though we are in a system that doesn't mean that we can't do it.

\section{Encourage Us}

The third theme, "encourage us" was a powerful and consistent theme across all stations. Throughout many of the participants' stories, the theme of caring adults outside of the home had a significant impact on participants' motivation and desire to change. For most of the participants this support came from community members, counselors, teachers, and administrators. Conceptually, when participants were encouraged, they were able to access their inner strengths that helped them get through the day, weeks, and months of staying in the CCP, out of trouble with the law, and away from poor peer influences. A station one participant stated, "they never knew from one moment to the next what was coming around the corner... we are confronted with life and death...once we walk into this place (CCP) we are immediately encouraged and acknowledged." The concept of perceived strength to survive was apparent for many of the participant stations, and it led many of them to remain hopeful that an opportunity and chance was possible.

Many participants agreed that they had received years of direct and indirect encouragement by OGs (original gangsters) and Big Homies (older friends in the community) and by cellmates to function as if they were in combat at all times and these adverse circumstances had surprisingly contributed to building strength. For station four, "counselors...like OGs and homies, helped us pull out those strengths and to reframe them for good and not bad." Station three also reflected this sentiment, "counselors and teachers taught us how to 'flow' (i.e., code blend), 'be able to flow in and out of spaces and places using our strengths - not put them down or embrace them." Many participants acknowledged the complexities they faced in life as well as the limited resources to correct the transgressions that accompanied their lifestyles. Others stated that street culture is responsible for the strength evidenced in the way they behave in school. The participants' ability to adapt to ever-changing environments was a direct result of the inner strength that was formed throughout their life experiences. 
Another means that students suggested of remedying inequities in career and college access and readiness was to simply inform them of opportunities that prepared them for college or allowed them to "earn college credit" (per station four). When asked what advice they would give other crossover students to prepare for college, station four participants reflected on what they wished they would have known regarding rigorous courses (i.e., AP and dual enrollment) courses when starting high school:

Like if they would've told us, ohh, like if you don't want to not waste that much money start taking harder classes from here on out, this is how many hours and this is how much money you're gonna save - encourage us and not keep us out of those classes. We can see other students in science class doing cool stuff we like cool stuff too...just give us a chance we are smart we just have other issues. We know we can act out from time to time, just be real with us - work it out with us.

\section{Administrator Researchers Reflection}

The four administrator researchers (all identifying as Latinx) were representative of the various systems serving crossover youth including one CWA administrator, one school-based Director of counseling services, and two JJA administrators, including one JJA who was the Director of education services for crossover students. Since conducting this research project, all four administrator researchers have played a role in facilitating other projects to help understand their district and department's needs. Below are personal reflections by all four of the administrator researchers showing the professional impact the project had on them. To protect the identities of administrator researchers, we will call them Admin1 through Admin 4.

Admin 1 is a 19-year veteran of the district and student support services director. "I was chosen to be in the project by the lead author (facilitator). I met the facilitator when I was supervising him when he was a district counselor for our district. I was responsible for the development of a couple [of] specialized programs for the district. Reflecting on the process for the CCP it was very different, I looked at school level data but [had] never been in a space that allowed me to process and reflect on what we could do to really target a group of kids with JJA - to really focus. At the beginning I was a bit apprehensive...not about the work, but the time I would have to give up scared me - but I was game as well as the other administrators. During the beginning, it was hard to think about what questions we wanted to ask and what the project would become. [The] facilitator just wanted us to think about how we came together to put the CCP together as well as what were some gaps and areas of success. We started off by sharing our vision and missions and how we came together. Historically this population, when they [society, schools] have problems with them they end up getting "pushed out," sent to camp, (or) going to continuation school. And these centers have not been structured as ... learning academies, it starts off with the name itself [detention centers]. Schools for kids ... that the system have failed. These are learning academies, which is a different approach, a different mindset. You have quality teachers there, rich programming there, and you combine that with the fact that the kids are in a real caring environment; I've seen the difference in the kids in the few times I've been in the centers speaking with them. The kids feel safe, they feel like they can learn there, so they're really not structured like the continuation schools where kids go because they got kicked out, and that's where they end up.... The small learning environments, they're designed with a very specific target population in mind, but they're there to be given all the resources possible to be successful. Not like a continuation school, [where] you're there because you got in trouble necessarily. We all thought the same things - we wanted to make an impact in our community. We worked hard every weekend to make our project really happen. I think by being a part of this project it has given me different points of views on things that crossover students go through on a day-to-day basis. It's given me opportunity and a sense of even more focus....direction for us as leaders. Most importantly is this project has taught me how to speak up for 
crossovers and educate other administrators, educators, teachers, and counselors across the district... as well as other agencies and partners (personal communication April 12, 2017).”

Admin 2 is a 22-year veteran of CWA who discusses the importance of open and collaborative cultures during this process. "I believe creating the change necessary to provide the resources and services for crossovers takes a team and requires leaders to create a culture that is vulnerable, open, and honest with each other. These leaders work to encourage and develop other leaders who will then develop more leaders; overtime coherence is achieved across several iterations of the innovation (CCP). Leadership is really important, and the teachers have been hand-selected to be a part of this program. (They) actually like working with students, and they have the passion for working with this population of students. They're very patient and they're not judgmental. And because the adults always create the barriers for students, the people that we've hand-selected are welcoming, and it's a safe learning environment. The kids feel comfortable, they don't feel judged and some of the students we've interviewed for videos that we've put together to try to promote the work we're doing, they'll tell you 'my counselor told me that I could graduate. There was a student that said that she thought that her counselor was calling her parents to complain about her and the fact that she wasn't in school, and she was surprised that the counselor wanted to help her and wanted to support her, and that's why she came back to school. It's a lot about leadership and the fact that they believe in these kids (personal communication, April 12, 2017)."

Admin 3 is a 12-year veteran of the school district and director of counseling services. "Historically, schools have struggled to keep students interested in the topics the schools are teaching. By deepening learning, the students are not just being fed information from the teachers but are learning to learn or thinking about the way they think and make decisions. The students are engaged in their work and feel connected not only to each other but also the community as a whole. The focus and collaboration within JJA has been directed towards the improvement of the learning-teaching process. USD has found that the general education communities have not been working towards engaging crossovers in the district. We believe we have a model that we feel is working and we've been collecting student academic data, and we're seeing that there's improvement in reengagement, so kids are enrolling and staying in. We've looked at their attendance and they're staying in school, and we've also looked at credit approval and what we realized is when we compare credit accrual and students who are enrolled in a small learning environment, they're accruing more credits in the small learning environment, as opposed to the students enrolled in a large comprehensive high school. What we're thinking is that they're receiving comprehensive support, but it's more of a personalized small learning environment (personal communication, April 12, 2017).”

Admin 4 is a 16-year veteran of JJA and director of educational services for crossover students. "Coming together professionally, as well as personally, provides a level of comfort when needing to reach out to various team members. Even though many of us met for the first time through this partnership, we now feel comfortable reaching out to one another. When it comes to... cutting red tape or overcoming a roadblock, it's that personal relationship that allows us to be able to pick up the phone and feel comfortable calling anybody; any one of the team members to say 'you know what? There's a problem; how do we fix it?'. And it's actually gone beyond what started out as pretty simple 'how do we help get our kids into school' now it's grown to a bigger picture and really involving the entire system. The top of our organization to the folks on the ground that are actually doing the work, it's really getting not just the system leaders involved but we have the meet-and-greets that is to personalize the process. It isn't, 'here's this list; call this person when you run into a problem'. It becomes, 'these are real people, that are professionals like you and our goals are all the same, we share a common goal so we get to know each other because these are the folks that you're going to turn to when you come across an obstacle. It helps to keep people accountable because the accountability comes from being familiar with one another. It's one thing to disappoint someone you don't know, very different from disappointing someone that you know 
and have built a relationship with. When it comes to being responsive to them and everything else it allows individuals to be that much more responsive knowing the face behind the name of the emails that they frequent (personal communication, April 12, 2017)"”

\section{Discussion}

This PAR study explored the experiences of crossover youth and administrators engaging in a CCP in a major west coast urban school district and the support systems needed in order to advocate for such programming. This article provides insights from administrator researchers, participants, and the authors as well as provides recommendations for school leadership, counselors, and organizations who are thinking of creating more support and educational opportunities for crossover students through an advocacy lens.

Through this article, the authors aim to share the findings of this study to address the impact of educational barriers that impede the collaborative process between students and counselors in supporting the CC needs of crossover students. Identifying the promotive and protective recourses of these youth early can influence a student's postsecondary pathway regardless of their status. We strongly recommend interagency collaboration and advocacy to improve programming, counseling services, and responsiveness to crossover youth. However, the identification and focus on crossover or dually involved youth across multiple agencies is a relatively new frontier. Community collaboration across these three systems is difficult to accomplish for a variety of reasons, including differing infrastructures, information privacy policies, and competing priorities (Herz et al., 2012), and as such, is not often accomplished. Very few studies have investigated these interagency collaborations, but these results suggest that there may be positive outcomes such as better identification of crossover youth, more efficient counseling service delivery, and improved collective collaboration as a part of CCP efforts (Haight et al., 2014). Consistent with the ACA-ACM (Lewis et al., 2003; Toporek \& Daniels, 2018) the current study demonstrates the effectiveness of employing a multifaceted approach that enlists participation from students, counselors and administrators for eliciting practical solutions for overcoming environmental barriers to student achievement. The solutions were elicited through a participatory strength-based research process that emphasized the value added by collaborating with community partners and crossover youth.

These recommendations, while supported by literature examining the schooling experiences of crossover youth, are also reflective of similar needs of students-of-color (Franquiz \& Salazar, 2004). Thus, it would seem obvious to recommend hiring more staff, particularly at schools that serve crossover youth. However, many schools face financial constraints that often deem counselors as discretionary personnel (McDonough, 2005). Increasing the number of counselors on high school campuses, however, does not ensure counselors understand and meet the needs of the diverse students they serve. To strengthen systems level advocacy, counselors must be held accountable and purposefully build trusting, authentic, and radical relationships with crossover youth. This recommendation is consistent with the National Education Association (NEA), American Association of School Administrators (AASA), and American Counseling Association's (ACA) multicultural competencies (Ratts et al., 2015) that indicate counselors and administrators must be knowledgeable about students they work with, the cultural assets of these students and their families, and specifically be cognizant of the heterogeneity that exists within racial/ethnic groups so as to not assume or attach stereotypes to students based on any demographic characteristics. Along these same lines, administrators recommended that counselors and teachers provide crossover students with personalized support for each student. The administrators also held themselves accountable for strengthening the quality of their relationships with teachers and counselors referred to as "boots on the ground." This seemed to reflect their belief that authentic personalized relationships (e.g., learning the names of personnel, participating in meet-and-greets) could potentially enhance the quality of collaborative services provided by administrators and school personnel. 


\section{Facilitator Reflection}

As noted above, CCP project was facilitated by the first author who had supported this group of four veteran administrators with multiple years of experience. I was asked to facilitate this project due to my deep understanding of the population, district, and issues of the community working with high school crossover students transitioning back into school settings. These are my reflections and suggestions for other facilitators who are embedded in schools and interested in CCPs and supporting crossover student preparation and readiness for postsecondary pathways and life after high school.

\section{Facilitator Suggestions}

CCP project provided an environment where administrator researchers could not only engage in the process of informing system change for crossover youths around the district and community but also actively engage in their own collective and individual professional development. As a school counselor educator and the facilitator of this process, I was able to facilitate the development of new ideas and strategies to support the academic, career, and social/emotional needs of crossover students preparing for life after high school. Here, I provide suggestions for other counselors who are interested in serving as facilitators who might be delving into CCP type work for the first time and who are interested in supporting crossover students' postsecondary pathways.

Simulate college and career classes. Participants displayed strengths including assertiveness, curiosity, and confidence in themselves. Participants were particularly interested in understanding the content, format, and styles of a college class. Crossover youths in the CCP have the aspirations and desire(s) of attending postsecondary pathways and recognized the CCP could simulate the way a college course would be delivered. Participants also wanted to visit college classrooms and learn what a day in the life of a college student feels like. Participants wanted to make sure that counselors, teachers, and administrators understand that, "even though they may be behind, they still want to be exposed." Also, don't be afraid of being "real" with them about the road ahead of them. Talk to crossover youths about multiple pathways (i.e., trade and vocational schools at the community college and military options).

Actively involve crossover youth in the decision-making process. Driving decision-making based on (a) engaging crossover students and their families based on their developmental stages and with respect to their culture and (b) prioritizing crossover and family voices and experiences were key takeaways from participants and administrator researchers. The facilitator assisted the students in identifying environmental barriers to their development and recommending solutions for overcoming these barriers. An expanded definition of family is necessary in order to identify and include the appropriate people who can support crossover success. This group of supportive individuals may include nontraditional positive adult influences who are able to contact and visit the youth in multiple settings (i.e., school, court, and camps). Families should be included in educational case planning and treatment and have a meaningful say in the goals and case plans. Counselors, teachers, and administrators should engage students and their families/caretakers as early and as often in college and career planning. Educational support and professional development should be provided for teachers, administrators, and counselors as well as individualized by their professional needs. Counselors should make sure student and family educational rights are known and respected. Developing and circulating/posting a student and family bill of rights would show that the school counseling team is open and willing to take care of the student as well as their family.

Finally, multidisciplinary teams (MDTs) for crossover students can drive case planning and are structured to facilitate collaboration across multiple agencies. In order for this to be successful, all staff across all agencies must be trained in the therapeutic/educational model (including kitchen staff, maintenance, teachers, probation officers, etc.). This necessitates cross-training that recognizes there is no separation of staff roles in supporting program goals. All direct care providers (i.e., counselors) will be trained to support the education, 
therapeutic, and rehabilitative components of the CCP project and are expected to actively participate in the program. In order to successfully incorporate all programming elements in a holistic and integrated manner, staffing patterns and schedules will need to accommodate regular (weekly) multidisciplinary team meetings, and allow sufficient time for planning and debriefing activities.

Provide strengths-based engaged programming. Programming for crossover students should be meaningful for students and staff with a focus on skill-building, mental health, academic, and college and career growth. Programming should always build on students' current strengths and resources and identify opportunities and linkages in the community (i.e., program or employment opportunities) to support the students' self-identified strengths and goals while in the CCP program and upon reentry into a comprehensive high school. Programming must include community-based organizations with direct contacts in the communities which students will return to and support during and after high school. Participants recommended skills training using mindfulness practices, learning how to balance their emotions, and establishing positive relationships. Administrator researchers recognized the importance of cognitive-behavioral and dialectical skills training for students as well as making sure all staff were trained in creating trauma-informed/sensitive programming. Participants also suggested that counselors would benefit from learning how to run groups in the classroom that gave them skills to interview for jobs, complete a college and financial aid (FAFSA) application, and enhance their confidence and agency to attend college and be career ready through programming. With regard to their learner role, participants recommended that counselors help them to understand the components of how to engage in positive academic and metacognitive strategies, connect the utility of what is being taught and relate course content with future work, and commit to helping them develop interpersonal skills to navigate dysregulation.

Recognize and address the racial and ethnic disparities related to the access of services. Participants all indicated that it would benefit counselors to be trained on implicit bias and best practices in reducing racial and ethnic disparities. Ensuring that gender responsive services are available to all students and that there is a coordinated effort between agencies to work with community organizations to bridge this gap. Administrator researchers realized that they needed to assess the level of availability of services by taking an inventory of services in each domain (academic, career, and social/emotional). As well as document the availability of services relative to the needs of families and students to determine if there is an adequate "fit" in the students and schools' goals and what needs are currently unmet. Finally, they will also evaluate the services available to assess which services are beneficial to helping families and youth and which ones should be abandoned in favor of more effective programming.

Emphasize academic achievement and engagement. Academic achievement and engagement are critical to each youth's program, and input from education providers is a fundamental element of case and reentry planning. A rigorous and relevant education program is viewed as the locus of personal development for every student at the CCP campus and is understood to be at the core of the program. Administrator researchers recognized the importance of their counselors with regard to supporting students' perceptions of self and promoting their confidence and desire to change their life trajectory through education and rediscovery of passion and purpose. CCP school counselors should provide college and career readiness training to help crossover students navigate the educational system through hands-on techniques and skills. School counselors should use motivational interviewing to help students build on positive interpersonal interactions with others. School counselors and teachers will continue to use restorative practices and pathways to facilitate a process of healing and establishing positive family relationships that are nurturing. School counselors and teachers will support and assist students in enrolling in an appropriate secondary education environment as well as a postsecondary program that leads to career and job success during and after high school. School counselors and 
teachers will work on Individualized Learning Plans (ILPs) and provide core curriculum lessons on college and career readiness planning.

The education program of the CCP is rooted in social-emotional connections to content. The core education program would benefit from tiered intervention (e.g., simultaneously providing individual, school, and community-based interventions) to allow students to make major educational improvements, and complete credit recovery courses. CCP employs a behavior intervention system to encourage positive behavior that allows students to improve their educational scores. School counselors are able to come together to develop their core curriculum lessons in a professional learning community. Students could benefit from moving through a thematic, interdisciplinary, and project-based framework with themes that focus on self-esteem, empowerment, hope, transformation, and new beginnings, which in turn, collectively support the social and emotional needs of students. At the end of each thematic unit, an exhibition can be held where students present to other students, staff, and the community, providing them the opportunity to gain leadership skills and have ownership over their learning. Every student will leave with a portfolio of their credits, workshops, and certificates. Also, inviting community partners to serve as experts in order to enhance the curriculum would make the experience more realistic for students. Creating a pathway for higher education through the curriculum, with the goal of postsecondary preparation in mind, is at the forefront of each topic and conversation with students. Eligible students who are either enrolled in high school or have already graduated from high school are offered online college courses and career technical education. The goal is for each student to be ready for a job, the military, or higher education once they are back in their own community. School counselors and counselors must function as leaders that guide the vision of the school. They will provide instructional guidance, based on cultural needs, classroom support, coaching, and professional development, to teachers and administrators. Finally, counselors will integrate visual and performing arts of all kinds into all counseling programming and academic learning time as well as out-of-class time via partnerships with artists and arts educators.

\section{Limitations}

The first limitation of this study centered on not having enough time to capture the complete lived experiences of the participants. The CCP leaders who participated for this investigation lead two major programs for the district and county, limiting the time to two months. As a result, this two-month time frame limited the exposure or time needed to see how the CCP program impacted crossover youth participants on a daily-basis as well as how much time we had with all involved parties for the study. According to Van Manen (1990), the experience of time, the reflection on past time, and anticipated time to come are essential components of a hermeneutic phenomenological study. The reflection, anticipation, and experience of time are essential because the insight into the essence of a phenomenon involves a process of reflecting, clarifying, and making clear meaning of the lived experience (Van Manen, 1990). In other words, additional time or a more extended investigation would have helped the participants explicitly unveil their lifeworld as they would usually experience (Kafle, 2011; Van Manen, 1990). However, to mitigate this limitation, the participants were asked to reflect upon their roles as participants in the CCP based on the prior 10-month school year in their journals, providing further insight into the phenomenon under study.

An ongoing challenge faced by hermeneutic phenomenological researchers is to reduce the bias they bring to an investigation (Cohen et al., 2000). This issue can present a challenge for hermeneutic phenomenological researchers because the study's structure mandates that data must be reported and documented precisely as it happens rather than based on their opinions (Cohen et al., 2000). To mitigate this limitation, the researcher utilized two evidence-based techniques during the hermeneutic phenomenological study: bracketing and a research audit trail.

Bracketing is a methodological device of phenomenological inquiry that requires researchers to disregard their tenets, knowledge, and insight into the phenomenon they have under investigation (Chan et al., 2013). Equally as important, bracketing can demonstrate the validity of the data collection and analysis process 
(Chan et al., 2013). Chan et al. (2013) suggest that bracketing begins before the literature review because the literature review, data collection, and the analysis are sequentially related. Accordingly, the researcher kept an interactive journal about assumptions and beliefs on the phenomenon before the start of the investigation. Therefore, reducing bias during the investigation and demonstrating the validity of the data collection and analysis process.

A research audit trail refers to the hermeneutic phenomenological researcher documenting all decisions regarding the strategies utilized to conduct the investigation as well as his or her thought processes during the data analysis stage (Cohen et al., 2000). For this investigation, the researchers maintained two audit trails: a physical research audit trail and an intellectual research audit trail. The physical audit trail documented the stages of the research study and reflected on the implementation of crucial research methodology decisions. The intellectual research audit trail helped the researcher to reflect on how his or her thinking evolved throughout the qualitative study. Furthermore, the two audit trails (1) increased research transparency, (2) presented a useful strategy for determining the trustworthiness of a hermeneutic phenomenological study, and (3) confirmed the research findings (Carcary, 2009). Consequently, the two audit trails will eliminate any potential threats to validity.

\section{Conclusion}

As the educational disparities between crossover and mainstream youth become more apparent both through attention from scholars and from mainstream media, teachers, counselor and administrators will become more sensitive to their needs and thus more apt to find ways to assist them in reaching their highest potential. The often quoted saying, "It takes a whole village to raise a child" means it takes a communal effort to advocate and support the growth of these youth. This saying is especially true for crossover youth who must successfully navigate their way to adult self-sufficiency. This will not be possible without help from a strong support network and tools that will ensure both their personal and educational success. As counselors and teachers become more educated on the unique needs of crossover youth, they can play a lead role in these support networks that can help to meet their needs through unique programming models such as the CCP.

\section{Corresponding Author}

Correspondence concerning this article should be addressed to Dr. Robert R. Martinez, School of Education, The University of North Carolina at Chapel Hill, 1050F Peabody Hall (Box CB 3500), Chapel Hill, NC. 27599. E-mail: rrmartin@email.unc.edu. 


\section{References}

Abbott, S, \& Barnett, E. (2015). The crossover youth practice model (CYPM)-the CYPM in brief: Behavioral health and crossover youth. Retrieved from the Center for Juvenile Justice Reform. Retrieved from https://cjjr.georgetown.edu/wpcontent/uploads/2015//08/CYPM-Behavioral-Health-BriefFinal-8 6 16.pdf

Abbott, S., \& Barnett, E. (2016). The crossover youth practice model (CYPM). Available from http://cjir. georgetown.edu/

Alfred R. (2011). From community participation to organizational therapy? World Café and appreciative inquiry as research methods. Community Dev J., 46, 57-71.

Armour, M. P. (2002). Journal of family members of homicide victims: A qualitative study oftheir post homicide experience. American Journal of Orthopsychiatry 72(3), 372-83.

Balkin, R. S., \& Kleist, D. M. (2017). Counseling research: A practitioner-scholar approach. Alexandria, VA: American Counseling Association.

Braun V, \& Clarke V. (2006). Using thematic analysis in psychology. Qual Res Psychol, 3, 77-101.

Brown, D.R., Hernandez, A., Saint-Jean, G., Evans, S., Tafari, I., Brewster, L.G., et al. (2008). A participatory action research pilot study of urban health disparities using rapid assessment response and evaluation. American Journal of Public Health, 98(1), 28-3.

Carcary, M. (2009). The Research Audit Trial--Enhancing Trustworthiness in Qualitative Inquiry. Electronic Journal of Business Research Methods, 7(1).

Chan, Z. C., Fung, Y. L., \& Chien, W. T. (2013). Bracketing in phenomenology: Only undertaken in the data collection and analysis process. The qualitative report, 18(30), 1-9.

Children's Law Center of California (2010). CA fostering connections to success act (AB-12/212) fact sheet. Retrieved from http://leginfo.legislature.ca.gov/faces/billNavClient.xhtml?bill id=200920100AB12

Cohen, L., Manion, L., \& Morrison, K. (2000). Research methods in education (5th ed.). London: Routledge Falmer.

Davidson, L., Stayner, D. A., Lambert, S., Smith, P., \& Sledge, W. H. (1997). Phenomenological and participatory research on schizophrenia: Recovering the person in theory and practice. Journal of Social Issues, 53(4), 767-784.

Fishman, B. J. (2014). Designing usable interventions: bringing student perspectives to the table. Instructional Science, 42(1), 115-121.

Franquiz, M. E., \& Salazar, M. D. C. (2004). The transformative potential of humanizing pedagogy: Addressing the diverse needs of Chicano/Mexicano students. The High School Journal, 87(4), 36-53.

Freeman, M. (1997). Legislation and the courts. Dartmouth.

Gallegos, A. H., \& White, C. R. (2013). Preventing the school-justice connection for youth in foster care. Family Court Review, 51(3), 460-468.

Giorgi, A. (1997). The theory, practice, and evaluation of the phenomenological method as a qualitative research procedure. Journal of Phenomenological Psychology 28(2), 235-426.

Guba, E. G., \& Lincoln, Y. S. (2004). Competing paradigms in qualitative research. In: Denzin NK, Lincoln YS, eds. Handbook of Qualitative Research. Sage.

Hacker, K. (2013). Community-based participatory research. Sage.

Haight, W., Bidwell, L., Choi, W. S., \& Cho, M. (2016). An evaluation of the Crossover Youth Practice Model 
(CYPM): Recidivism outcomes for maltreated youth involved in the juvenile justice system. Children and Youth Services Review, 65, 78-85.

Herz, D. C., Lee, P. Lutz, L., Stewart, M., Tuell, J. \& Wiig, J. (2012). Addressing the needs of multisystem youth: Strengthening the connection between child welfare and juvenile justice. Retrieved from http://gcjjr.dcwdhost.com/wpcontent/uploads/2015/03/MultiSystemYouth_March2012.pdf

Herz, D. C. (2016). A summary of findings for the Los Angeles County 241.1 multidisciplinary team. Report presented to the Los Angeles board of supervisors. Retrieved from http://www.juvenilejusticeresearch. com/sites/default/files/2016-12/2015\%20Multidisciplinary\%20241\%20Report\%206-1-15.pdf

Hirschi, T. (1969). Causes of delinquency. University of California Press.

Jenson, J. M., \& Fraser, M. W. (2006). Social policy for children and families: A risk and resilience perspective. Sage Publications.

Kafle, N. P. (2011). Hermeneutic phenomenological research method simplified. Bodhi: An interdisciplinary journal, 5(1), 181-200.

Kidd, S. A., \& Kral, M. M. (2005). Practicing participatory action research. Journal of Counseling Psychology, 52, 187-195.

Lee, C. C. (1998). Counselors as agents for social change. In C. C. Lee \& G. R. Walz (Eds.), Social action: A mandate for counselors (pp. 3-16). American Counseling Association.

Lee, C C. (Ed.). (2007). Counseling for social justice (2 ${ }^{\text {nd }}$ ed.). ACA.

Leone, P., \& Weinberg, L. (2010). Addressing the unmet educational needs of children and youth in juvenile justice and child welfare systems. Georgetown University Center for Juvenile Justice Reform.

Lewis, J. A., Arnold, M. S., House, R., \& Toporek, R. L. (2003). ACA advocacy competencies. Retrieved from https://www.counseling.org/docs/default-source/competencies/aca-advocacy-competencies-updatedmay-2020.pdf?sfvrsn=f410212c 4

Lutz, L., Stewart, M., Legters, L., \& Herz, D. (2010). The crossover youth practice model: Center for Juvenile Justice Reform. Georgetown University McCourt School of Public Policy.

McDonough, P. M. (2005). Counseling and college counseling in America and prospects. National Association for College Admission Counseling.

McIntyre, A. (2007). Participatory action research (Vol. 52). Sage Publications.

New York City Office of the Mayor, Center for Innovation through Data Intelligence (2015). Young adult outcomes of foster care, justice, and dually involved youth in New York City. Retrieved from http://www. nyc.gov/html/cidi/downloads/pdf/foster- care-justice-dually-involved-report.pdf on August 20, 2019.

Nurse, A. M. (2013). Juveniles and college: Inside out as a way forward. The Prison Journal, 93(2), $234-247$.

Office of Juvenile Justice and Delinquency Prevention [OJJDP]. (2016). Juvenile drug court programs. JAIBG bulletin. Retrieved from: http://www.ojjdp.gov/pubs/250083.pdf

Olafson, E., Goldman, J. H., \& Gonzalez, C. (2016). Trauma-informed collaborations among juvenile justice and other child-serving systems: An update. Journal of Juvenile Justice, 5(1), 1-13.

Osborn, D. S., \& Belle, J. G. (2018). Preparing juvenile offenders for college and career readiness: A cognitive information processing approach. Journal of Educational and Psychological Consultation, 93(2), 234247.

Patten, M.Q. (1990). Qualitative evaluation and research methods (2nd ed.). Newbury Park, CA: Sage. 
Pérez, A., \& Teasley, M. (2015). Improving educational outcomes of school-age children and youths involved in public systems. Children and Schools, 37(4), pp. 195-197.

Ratts, M. J., Singh, A. A., Nassar-McMillan, S., Butler, S. K., \& McCullough, J. R. (2015). Multicultural and social justice counseling competencies. Retrieved from https://www.counseling.org/knowledge-center on July 20, 2020.

Reason, P., \& Bradbury, H. (2012). The Sage handbook of action research: Participative inquiry and practice (2nd ed.). GB: Sage Publications Ltd.

Ryan, J., Williams, A. B., \& Courtney, M. E. (2013). Adolescent neglect, juvenile delinquency, and the risk of recidivism. Journal of Youth and Adolescence, 42(3), 454-465.

Sampson, R. J., \& Laub, J. H. (1993). Crime in the making: Pathways and turning points through life. Harvard University Press.

The Aspen Institute (2019). Opportunity youth network summit recap: Forum for community solutions. Retrieved from https://aspencommunitysolutions.org/opportunity-youth-network-summit-recap/

Toporek, R. L., \& Daniels, J. (2018). 2018 update and expansion of the 2003 ACA Advocacy Competencies: Honoring the work of the past and contextualizing the present. Retrieved from www.counseling.org on July 20, 2020.

Van Manen, M. (1990). Beyond assumptions: Shifting the limits of action research. Theory into practice, 29(3), 152-157.

Wells, R., Gifford, E., Bai, Y., \& Corra, A. (2015). A network perspective on dropout prevention in two cities. Educational Administration Quarterly, 51(1), 27-57.

Wylie, L. (2014). Closing the crossover gap: Amending fostering connections to provide independent living services for foster youth who crossover to the justice system. Family Court Review, 52(2), 298-315.

Young, D., Bowley, A., Bilanain, J., \& Ho, A. (2015). Traversing two systems: An assessment of crossover youth in Maryland. Department of Justice. 